\title{
Task-Dependent Modulation of Regions in the Left Inferior Frontal Cortex during Semantic Processing
}

\author{
A. L. Roskies ${ }^{1}$, J. A. Fiez ${ }^{2}$, D. A. Balota ${ }^{3}$, M. E. Raichle ${ }^{3}$, and S. E. Petersen ${ }^{3}$
}

\begin{abstract}
To distinguish areas involved in the processing of word meaning (semantics) from other regions involved in lexical processing more generally, subjects were scanned with positron emission tomography (PET) while performing lexical tasks, three of which required varying degrees of semantic analysis and one that required phonological analysis. Three closely apposed regions in the left inferior frontal cortex and one in the right cerebellum were significantly active above baseline in the semantic tasks, but not in the nonsemantic task. The activity in two of the frontal regions was modulated by the difficulty of the
\end{abstract}

\section{INTRODUCTION}

Our ability to associate rich representations with arbitrary symbols, and to access and manipulate those representations via these symbols, underlies everything from private thought to public discourse, from reason to communication. Given the centrality of language in human cognition and the foundational role semantics plays in language, surprisingly little is understood about the neural basis of the representation and processing of meaning.

Until recently, patients with brain lesions provided the only direct means for studying the neural basis of language processing. Lesion-behavior studies of individuals with impaired speech by Broca, Wernicke, and others provided the basis for the classical model of language processing, which holds that information flows from posterior to anterior regions for language comprehension and production (see Caplan, 1987).

While lesion studies have remained one of the principal methods for identifying functional roles of brain regions in language, a number of difficulties accompany the interpretation of lesion-behavior data. Failure to perform a task normally might imply that a damaged region is necessary for that function; alternatively, the deficit may instead result from nonspecific or interactive damage, injury to fibers of passage between distant regions involved in the function, or disturbance of an

\footnotetext{
${ }^{1}$ Massachusetts Institute of Technology, ${ }^{2}$ University of Pittsburgh, ${ }^{3}$ Washington University
}

semantic judgment. Other regions, including some in the left temporal cortex and the cerebellum, were active across all four language tasks. Thus, in addition to a number of regions known to be active during language processing, regions in the left inferior frontal cortex were specifically recruited during semantic processing in a task-dependent manner. A region in the right cerebellum may be functionally related to those in the left inferior frontal cortex. Discussion focuses on the implications of these results for current views regarding neural substrates of semantic processing.

early step in a serial processing stream. In addition, few aphasia studies include detailed anatomical localization of the lesion with magnetic resonance (MR) or post mortem analysis. Consequently, the literature often presents apparently conflicting accounts of the effects of damage to various brain regions.

Noninvasive functional brain imaging methods, while subject to their own constraints, escape many of the difficulties that accompany lesion-behavior studies, and thus offer complementary tools for the study of language. Neuroimaging data acquired during the performance of semantic tasks suggest an alternative framework for understanding language. Although a few studies are consistent with the classical model of semantic processing, arguing for the superior and middle temporal involvement in the processing of word meaning (Price, Moore, Humphreys, \& Wise, 1997; Vandenberghe, Price, Wise, Josephs, \& Frackowiak, 1996; Wise et al., 1991), many more have suggested that left inferior frontal regions are involved in lexical semantic processing (Poldrack et al., 1999; Gabrieli, Poldrack, \& Desmond, 1998; Binder et al., 1997; Wagner, Desmond, Demb, Glover, \& Gabrieli, 1997; Gabrieli et al., 1996; Demb et al., 1995; Klein, Milner, Zatorre, Meyer, \& Evans, 1995; Kapur et al., 1994; Petersen, Fox, Posner, Mintun, \& Raichle, 1989). The converging evidence prompts a focused exploration of the brain areas involved in semantic tasks. Are different brain regions used for highly automatic semantic judgments as well as more demanding, analytical semantic ones? Does left inferior frontal activation scale with task difficulty? To explore these questions, we 
used positron emission tomography (PET) to scan subjects performing lexical tasks requiring various degrees of semantic analysis. Comparison between patterns of brain activation elicited by these tasks enabled us to identify regions involved in semantic analysis in a taskdependent manner.

\section{RESULTS}

\section{Task Rationale}

Two pairs of tasks were designed to provide converging evidence for brain regions involved in semantic processing. The first pair, a "synonym" task and a "rhyme" task, both involve comparison between word features. For the semantic synonym task, subjects indicated whether the two words had the same meaning, while for the phonological rhyme task, they indicated whether the two words rhymed. Comparison of these two tasks was used to differentiate regions active during semantic or phonological processing from those regions active in lexical processing tasks more generally.

The second pair of tasks, "easy" and "hard" categorization, was designed to manipulate the semantic difficulty of the decision while keeping the type of task and surface features constant. Again, pairs of words were presented: the top word was the name of a category, and the bottom was a potential exemplar. For each word pair, the subject decided whether the bottom item was a member of the presented category. The difficulty of the decision differed between the tasks. In the easy categorization task, targets ("yes" trials) consisted of prototypical members of the category (e.g., bird-robin), and lures ("no" trials) consisted of items that had little or no semantic relation to category members (e.g., furnitureapple). In the hard categorization task, targets were less typical category members (e.g., bird-ostrich), and lures were category nonmembers that nonetheless shared many features characteristic of category members (e.g., furniture-stove). The same category and exemplar words were used in both the easy and hard tasks; differences in the pairings between category and exemplar determined the difficulty of the semantic decisions. Thus, the overall surface features of these tasks were identical (Figure 1).

In all tasks, pairs of words were presented visually, and subjects had to make a yes/no decision about the relationship between the words, indicated by pressing one of two keys with the right index or middle fingers. Half the trials in each block required a "yes" response and half required a "no" response. Reaction times (RT) and responses were recorded during all scanning sessions. All stimulus words were nouns, matched for word
Figure 1. Sample stimulus lists for the tasks. For synonym and rhyme tasks, two words were presented; the correct response is listed under $\mathrm{R}$ ( $\mathrm{y}=$ yes; $\mathrm{n}=$ no). The similarly shaded regions emphasize that the same words are used as exemplars in both easy and hard categorization tasks, and both as targets and lures.

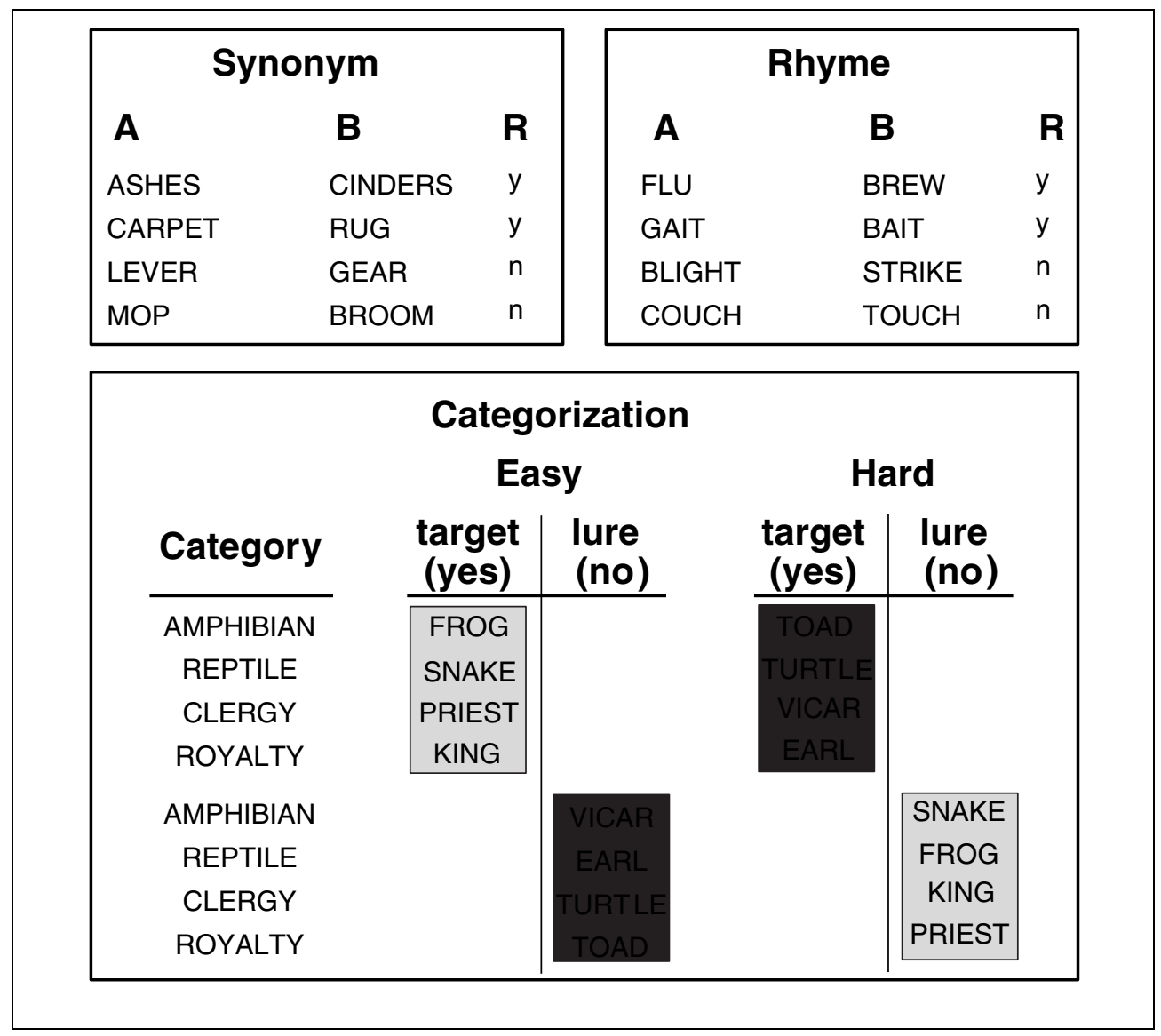


frequency (Francis \& Kucera, 1982) and word length across lists (see Methods).

\section{Outline of Analysis}

The detailed characterization of the results of this experiment required a series of analyses: (1) Behavioral analysis involved computing subjects' mean RT and response accuracy in each of the four tasks. (2) Global analysis of the PET data involved generating regions of interest (ROIs) by comparing scan results of the synonym and rhyme tasks. (3) These regions were then tested in the hard and easy categorization conditions and (4) these two conditions were directly compared. (5) Regions active in the rhyme but not the semantic conditions were examined, (6) as were regions that were active across all four language tasks.

To explore more fully the role of the left temporal cortex in semantic processing, (7) the temporal regions of peak activation were analyzed in more detail, and (8) the ROIs taken from the imaging literature were examined. (9) Finally, the data were assessed for sex differences in the patterns of activation generated by these language tasks.

\section{Behavior}

Mean RTs and accuracy were calculated for each condition (Figure 2). Differences in mean RTs between synonym (mean RT $=1114 \pm 51 \mathrm{msec} S E$ ) and rhyme (mean RT $=1041 \pm 45 \mathrm{msec} S E$ ) revealed that subjects were slightly but reliably slower and less accurate for

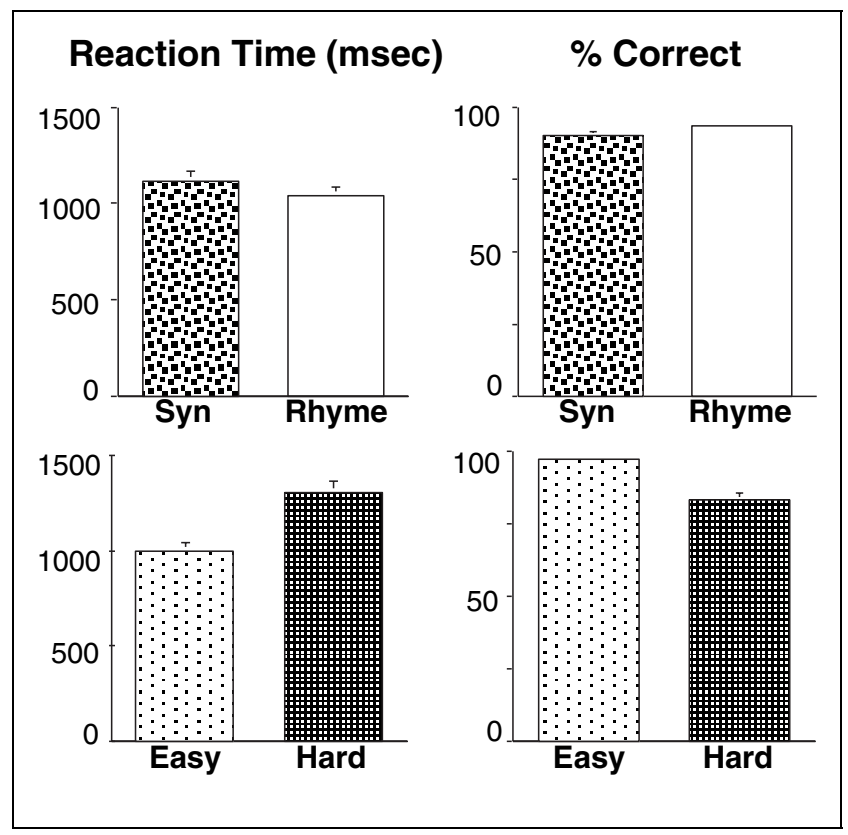

Figure 2. Behavioral results. Mean RTs and percent correct are shown. The synonym and rhyme tasks were of comparable difficulty, while the hard categorization task was substantially more difficult than the easy categorization task. synonym than for rhyme (paired $t$ test on RTs, $t(19)=$ $2.35, p=.029$; paired $t$ test on accuracy, $t(19)=2.28$, $p=.034)$. In contrast, responses to hard categorization trials took significantly longer than to easy categorization trials $[t(19)=10.13, p<.0001]$ and subjects were significantly less accurate, $t(19)=6.14, p<.0001$. Comparison of easy categorization with rhyme revealed no response time difference $[t(19)=1.01, p=.32]$ although subjects were significantly more accurate in the easy categorization condition, $t(19)=4.42, p=.0003$.

\section{Generation of ROI: Synonym-Rhyme}

In order to circumvent statistical problems incurred by multiple comparisons in data sets with thousands of voxels, data were analyzed in two stages, an initial stage to identify ROIs likely to be involved in semantic processing, and a second stage in which identified ROIs are tested on other semantic tasks in order to further constrain the interpretation of their function.

Comparison of tasks matched for surface features and most task characteristics would identify candidate brain regions related to the task differences, rather than incidental surface features; regions related to aspects common to both tasks, such as the processing of visually presented words, making a key press response, and so on, would be likely to be subtracted out. We began by identifying regions significantly more active in a semantic synonym task than in a nonsemantic rhyme task. A mean synonym-rhyme difference image was computed by averaging together individual synonym-rhyme difference images across subjects, with each subject contributing equal weight (following Shulman, 1997).

ROIs were determined by finding peaks of activation in the mean difference image (Mintun, Fox, \& Raichle, 1989). Twenty-two regions of positive activation with a magnitude of 40 or more counts and a $p$ value of $<.05$ in the synonym-rhyme image were found, including the left precentral gyrus (Broca's area), a number of areas in the left frontal lobe, and the regions in left temporal cortex, the cingulate gyrus, and the right cerebellum (Table 1).

\section{Testing ROIs: Semantic Conditions Versus Fixation}

The regions identified using the synonym-rhyme images are associated with the differences between these two tasks. These differences could be due either to the different demands upon semantic analysis required by the two tasks, or to other task differences, including subtle surface features, memory demands, task difficulty, attentional demands, etc. Corroborating evidence that these activations corresponded specifically to semantic processing was sought by using a converging operations approach: Activity at ROIs specifically associated with semantic processing should be increased in other semantic conditions with respect to 
Table 1. Regions More Active in Synonym Than Rhyme

\begin{tabular}{|c|c|c|c|c|c|}
\hline Coordinates & Region & Mean & $S E$ & $t$ & $p$ \\
\hline$-0.9,-24.8,-17.6$ & brainstem & 61 & 18 & 2.953 & .0043 \\
\hline$-11.2,63.1,2.2$ & left medial frontal gyrus BA 10 & 41 & 13 & 3.131 & .0029 \\
\hline$-13.0,47.0,30.2$ & left medial frontal gyrus BA 9 & 41 & 10 & 4.259 & .0002 \\
\hline$-22.7,19.4,38.2$ & left superior frontal BA 8 & 48 & 19 & 2.482 & .0113 \\
\hline$-25.1,-1.1,30.1$ & left precentral BA $6 / 44$ & 43 & 12 & 3.507 & .0012 \\
\hline$-25.1,-21.2,-0.1$ & left globus pallidus/putamen & 44 & 19 & 2.353 & .0148 \\
\hline$-34.6,24.9,-21.5$ & $?$ & 53 & 16 & 2.888 & .0054 \\
\hline$-37.0,23.1,-12.0$ & left inferior frontal BA 47 (medial) & 54 & 16 & 3.306 & .002 \\
\hline$-39.1,-59.0,29.7$ & left superior temporal gyrus BA 39 & 48 & 14 & 3.473 & .0013 \\
\hline$-40.9,41.0,-8.1$ & left inferior frontal BA 47 (anterior) & 44 & 18 & 2.486 & .0115 \\
\hline$-49.2,-6.7,-14.1$ & left inferior temporal gyrus BA 21 & 52 & 18 & 2.873 & .0051 \\
\hline$-5.0,40.9,-20.0$ & orbital gyrus BA 11 & 55 & 11 & 4.682 & .0001 \\
\hline$-5.2,27.2,-22.2$ & gyrus rectus BA 11 & 45 & 17 & 2.907 & .0051 \\
\hline$-50.9,8.9,46.1$ & precentral gyrus BA 6/8 & 41 & 15 & 2.503 & .0122 \\
\hline$-51.0,21.0,-2.0$ & left inferior frontal BA 47 (lateral) & 53 & 14 & 3.482 & .0013 \\
\hline$-6.9,-56.8,14.0$ & posterior cingulate BA 23 & 50 & 16 & 3.026 & .0035 \\
\hline $11.3,37.1,18.3$ & anterior cingulate BA 32 & 48 & 15 & 3.117 & .0028 \\
\hline $14.7,-84.9,-25.9$ & right posterior cerebellum & 41 & 16 & 1.997 & .0328 \\
\hline $19.4,12.7,43.8$ & right anterior cingulate BA $6 / 32$ & 41 & 18 & 2.103 & .0258 \\
\hline $36.9,-23.2,-20.0$ & hippocampal gyrus BA 36 & 42 & 19 & 2.147 & .0228 \\
\hline $53.2,3.1,-7.8$ & right medial temporal gyrus BA 21 & 41 & 17 & 2.476 & .0114 \\
\hline $7.2,-67.0,-25.8$ & right medial cerebellum & 60 & 21 & 2.674 & .0091 \\
\hline
\end{tabular}

baseline. Activity at each of the ROIs identified in the synonym-rhyme manipulation was assessed in individual difference images of each of the tasks versus fixation. Mean regional magnitudes for each task were computed for each ROI, and $p$ values were calculated for each region. Four ROIs were found to be significantly active above baseline $(p<.05)$ in the synonym and in the hard categorization condition (Table 2). Three of the regions are located in the left inferior frontal cortex, at or near Brodmann's area 47 (BA 47) (Figure 3). One of the regions is far anterior $(-41,41$, $-8)$, and two regions are near the left frontal operculum, one medial $(-37,23,-12)$ and one lateral $(-51,21,-2)$. The fourth region active across semantic conditions is in the right cerebellum $(15,-85$, $-26)$. Only 1 of the 3 regions in the left inferior frontal cortex was significantly active in the easy categorization condition relative to baseline, although the two others showed a trend toward activation.

Activation of ROIs during the categorization tasks provided further evidence that areas identified by com- parison of the synonym and rhyme tasks are involved in semantic processing.

\section{Comparison of Categorization Conditions}

We next asked whether the regions identified in our previous screens were differentially activated by the two categorization tasks (Figure 3). Both easy and hard categorization tasks employed the same corpus of words, but differed in the difficulty of the semantic decision, so we reasoned that if the identified regions were indeed involved in semantic processing, then they might be more strongly activated for the hard than the easy condition. A one-tailed paired $t$ test showed that the activation near the left medial operculum $(-37,23,-12)$ was not significantly different in the two categorization conditions, $t(17)=0.295, p=.61$. In contrast, the lateral opercular region $(-51,21,-2)$ was much more strongly active in the hard than the easy condition (mean difference $=41, t(17)=5.38, p<.0001)$, and the more anterior inferior frontal region $(-41,41,-8)$ showed a 
Table 2. Synonym-Rhyme Regions Also Active in Other Semantic Tasks

\begin{tabular}{|c|c|c|c|c|c|c|c|c|}
\hline \multirow[b]{2}{*}{ Coordinates } & \multicolumn{4}{|c|}{ Easy Categorization } & \multicolumn{4}{|c|}{ Hard Categorization } \\
\hline & Mean & $S E$ & $t$ & $p$ & Mean & $S E$ & $t$ & $p$ \\
\hline$-37.0,23.1,-12.0$ & 45 & 13 & 3.331 & .004 & 40 & 15 & 2.767 & .0132 \\
\hline$-40.9,41.0,-8.1$ & 23 & 14 & 1.681 & .111 & 50 & 10 & 4.975 & .0001 \\
\hline$-51.0,21.0,-2.0$ & 25 & 18 & 1.435 & .1693 & 66 & 16 & 4.164 & .0006 \\
\hline $14.7,-84.9,-25.9$ & 8 & 20 & 0.401 & .6948 & 58 & 17 & 3.35 & .0048 \\
\hline
\end{tabular}

\begin{tabular}{|c|c|c|c|c|c|c|c|c|}
\hline \multirow[b]{2}{*}{ Coordinates } & \multicolumn{4}{|c|}{ Synonym } & \multicolumn{4}{|c|}{ Rhyme } \\
\hline & Mean & $S E$ & $t$ & $p$ & Mean & $S E$ & $t$ & $p$ \\
\hline$-37.0,23.1,-12.0$ & 31 & 14 & 2.162 & .0452 & -13 & 16 & -0.807 & .4308 \\
\hline$-40.9,41.0,-8.1$ & 48 & 19 & 2.576 & .0196 & 5 & 20 & 0.255 & .8015 \\
\hline$-51.0,21.0,-2.0$ & 48 & 22 & 2.223 & .0401 & 3 & 11 & 0.28 & .7832 \\
\hline $14.7,-84.9,-25.9$ & 56 & 11 & 5.278 & .0001 & 21 & 17 & 1.267 & .2258 \\
\hline
\end{tabular}

trend toward differential activation (mean difference $=$ $27, t(17)=1.70, p=.054)$. In addition, the cerebellar region $(15,-85,-26)$ was significantly more active in the hard than easy condition (mean difference $=50$, $t(14)=2.09, p=.028$ ). (For potential interpretations of the role of cerebellum in language processing, see Fiez, 1996, and Desmond, Gabrieli, \& Glover, 1998). Graphical displays of activation in the four areas in each of the task conditions are presented in Figure 4.

\section{Regions More Active in Rhyming Than Semantic Judgments}

Because our experimental design does not include convergent phonological tasks, we lack the same interpretive leverage for identifying regions involved in phonological analysis as we have for those involved in semantic analysis. Nonetheless, by examining regions more active in the rhyme than the synonym task, we can identify candidate regions involved in phonological processing. Twenty-six activations in the rhyme-synonym mean difference image were found with a magnitude of 40 or more counts and a $p$ value of $<.05$. Of those, 11 were significantly active in rhyme with respect to baseline (Table 3). Several of these regions were not active in any of the semantic conditions, suggesting that they play a role in phonological processing. A region in the left middle insular cortex $(-37,-3,8)$ was active in the rhyme task, and inhibited in the semantic conditions with respect to baseline. Two regions in the left precentral gyrus (Broca's area; - 49, -1, 26 and -49, 3, 16) are located near activations reported from other phono-
Figure 3. Regions of activation in synonym-rhyme and categorization images. Mean difference PET images are shown in coronal slices at two cuts through frontal cortex (Talairach coordinates $y=41$ and $y=21$ ). Left: Three regions of significant activation in the left inferior frontal cortex are evident in the synonym-rhyme images (arrows). Middle and right: Hard and easy categorization data are shown with respect to fixation baseline. Middle: The same three left inferior frontal regions are noticeably active in the hard categorization condition. Right: In contrast, significant activation is only present in the lateral opercular area (bottom, shorter arrow) in the easy condition, while the two other regions are not active. Scale of PET counts is shown at left.

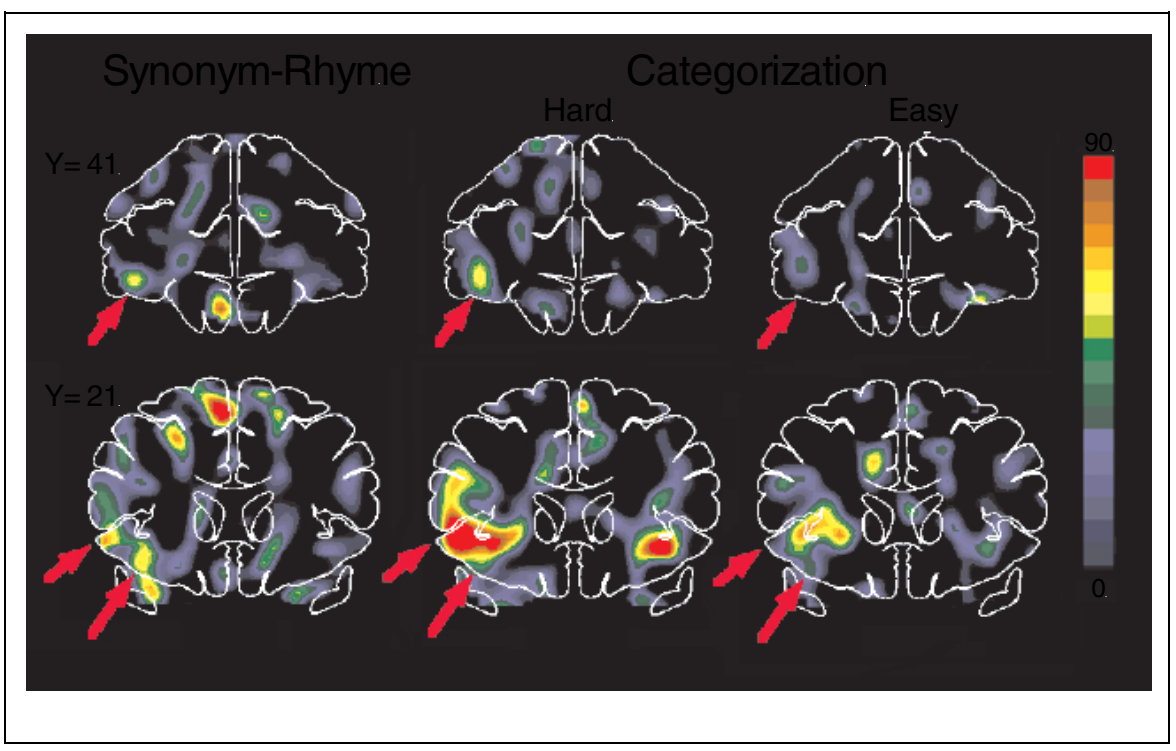


logical studies (Paulesu, Frith, \& Frackowiak, 1993; Zatorre, Evans, Meyer, \& Gjedde, 1992). A region in left motor cortex was more active in rhyme than the other conditions $(-55,-11,38)$, and may reflect mouth movement from subvocal articulation, although subjects were instructed not to articulate the rhyme stimuli. In addition, the right anterior thalamus was more active in rhyme than in the other conditions. Activation in other areas did not follow patterns expected of regions involved in semantic or phonological processes per se, and may instead reflect other processes not specifically tied to semantic or phonological analysis.

\section{Regions Active in All Four Language Tasks}

The four language tasks had many commonalities. To identify regions common to all these tasks, an image was created that was equally representative of all 4 conditions with respect to fixation: An average difference image for each of the 4 scan conditions was computed for every subject that had active-fixation scan pairs in all 4 conditions $(n=19)$, and then these 4 images were averaged across all subjects to form an intersubject global average difference image. Regions of peak activation were calculated, and all regions with an average magnitude of 20 counts or greater were further analyzed. The reliability of activation for each of the regions was assessed for each scan condition, and all regions that were significantly active above baseline with a value of $p<.01$ in each of the 4 conditions, as determined by a one-sample analysis, were considered to be significantly active across all 4 language tasks (Table 4). Regions were found in both hemispheres, although the majority was found in the left hemisphere. In the occipital cortex, peak activations were found in the primary and secondary visual cortex $(\mathrm{BA} 17,18)$ in the lingual gyrus. In addition, two regions in the left fusiform cortex (BA 37) were found, corresponding to regions previously found to be active in a number of studies involving word reading (Price et al., 1997; Petrides, Alivasatos, Meyer, \& Evans, 1993; Demonet et al., 1992; Wise et al., 1991; Petersen, Fox, Snyder, \& Raichle, 1990; Petersen, Fox, Posner, Mintun, \& Raichle, 1988, 1989). A region in the left middle temporal gyrus (BA 21) was active in all four conditions. In the frontal cortex, a region corresponding to Broca's area, and a more
Figure 4. Levels of activation of the three regions in left inferior prefrontal cortex and right cerebellum across tasks. $\mathrm{S}=$ synonym; $\mathrm{R}=$ rhyme; $\mathrm{H}=$ hard categorization; $\mathrm{E}=$ easy categorization.

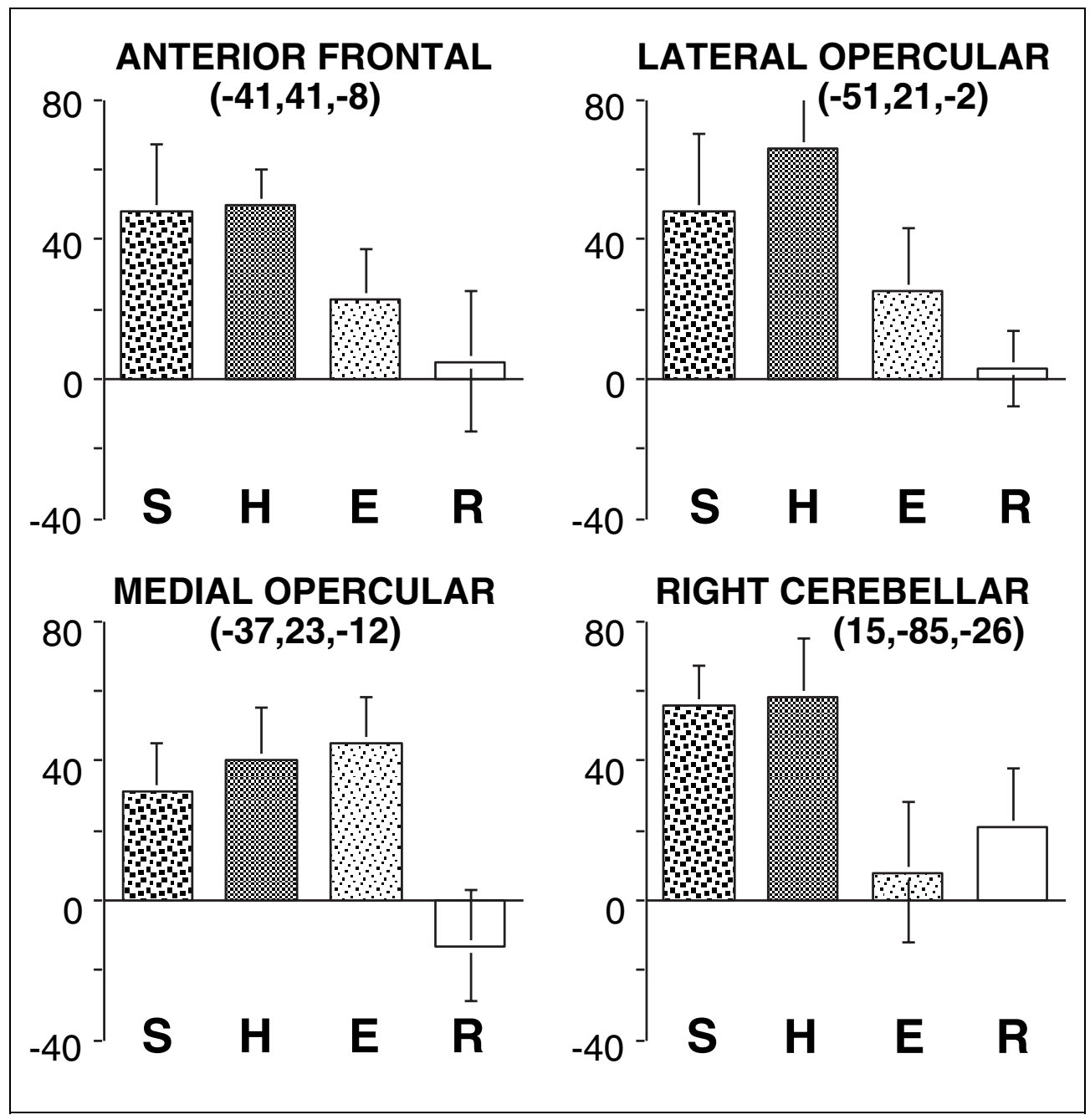


Table 3. Regions More Active in Rhyme Than Synonym

\begin{tabular}{|c|c|c|c|c|c|c|c|c|c|}
\hline \multirow[b]{2}{*}{ Coordinates } & \multirow[b]{2}{*}{ Region } & \multicolumn{4}{|c|}{ Easy Categorization } & \multicolumn{4}{|c|}{ Hard Categorization } \\
\hline & & Mean & $S E$ & $t$ & $p$ & Mean & $S E$ & $t$ & $p$ \\
\hline$-25,25,4$ & left anterior insula & 45 & 12 & 3.772 & .0014 & 33 & 14 & 2.306 & .0332 \\
\hline$-3,-9,6$ & dorsomedial thalamus & 4 & 19 & 0.221 & .8275 & 32 & 11 & 2.758 & .013 \\
\hline$-35,-71,-20$ & left middle cerebellum & 56 & 15 & 3.779 & .0014 & 59 & 14 & 4.369 & .0004 \\
\hline$-37,-3,8$ & left middle insula & -18 & 14 & -1.32 & .2043 & -28 & 16 & -1.768 & .0941 \\
\hline$-49,-1,26$ & left precentral BA 6 & 1 & 15 & 0.099 & .9225 & 18 & 13 & 1.347 & .1947 \\
\hline$-49,3,16$ & left precentral BA 6 & -6 & 13 & -0.46 & .65 & 4 & 10 & 0.367 & .7178 \\
\hline$-55,-11,38$ & left precentral BA 4 & -7 & 11 & -0.69 & .4996 & 18 & 13 & 1.38 & .1845 \\
\hline $15,-9,16$ & anterior thalamus & -18 & 14 & -1.26 & .2228 & 5 & 15 & 0.312 & .7584 \\
\hline $29,-67,-20$ & right middle cerebellum & 44 & 22 & 2.027 & .0577 & 49 & 18 & 2.737 & .0135 \\
\hline $31,-63,-29$ & right middle cerebellum & 69 & 32 & 2.153 & .0492 & 86 & 20 & 4.248 & .0008 \\
\hline $5,-67,2$ & extrastriate BA 18 & 26 & 13 & 2.073 & .0528 & 13 & 17 & 0.77 & .4514 \\
\hline
\end{tabular}

\begin{tabular}{|c|c|c|c|c|c|c|c|c|c|}
\hline \multirow[b]{2}{*}{ Coordinates } & \multirow[b]{2}{*}{ Region } & \multicolumn{4}{|c|}{ Synonym } & \multicolumn{4}{|c|}{ Rbyme } \\
\hline & & Mean & $S E$ & $t$ & $p$ & Mean & $S E$ & $t$ & $p$ \\
\hline$-25,25,4$ & left anterior insula & -4 & 16 & -0.22 & .8263 & 49 & 12 & 4.153 & .0006 \\
\hline$-3,-9,6$ & dorsomedial thalamus & 9 & 16 & 0.557 & .5844 & 37 & 15 & 2.489 & .0228 \\
\hline$-35,-71,-20$ & left middle cerebellum & 37 & 15 & 2.487 & .0229 & 53 & 11 & 4.93 & .0001 \\
\hline$-37,-3,8$ & left middle insula & -8 & 13 & -0.65 & .5251 & 33 & 14 & 2.311 & .0329 \\
\hline$-49,-1,26$ & left precentral BA 6 & -11 & 14 & -0.76 & .4582 & 45 & 11 & 4.059 & .0007 \\
\hline$-49,3,16$ & left precentral BA 6 & -16 & 14 & -1.14 & .2694 & 34 & 12 & 2.941 & .0087 \\
\hline$-55,-11,38$ & left precentral BA 4 & 2 & 12 & 0.163 & .8721 & 35 & 13 & 2.735 & .0136 \\
\hline $15,-9,16$ & anterior thalamus & -8 & 21 & -0.37 & .715 & 39 & 14 & 2.759 & .0129 \\
\hline $29,-67,-20$ & right middle cerebellum & 6 & 14 & 0.387 & .7031 & 81 & 14 & 5.892 & $<.0001$ \\
\hline $31,-63,-29$ & right middle cerebellum & 27 & 14 & 1.941 & .0726 & 94 & 28 & 3.314 & .0051 \\
\hline $5,-67,2$ & extrastriate BA 18 & 4 & 18 & 0.226 & .8238 & 53 & 16 & 3.315 & .0039 \\
\hline
\end{tabular}

superior region in the left precentral gyrus, thought to be involved in verbal encoding, were active, as was a region in the left frontal operculum, which has been detected in a wide variety of language tasks involving word analysis and production. The right frontal operculum was also active across tasks, but failed to meet the stringent $p<.01$ criterion in easy categorization minus fixation. On the midline, the anterior cingulate was consistently active. A number of regions in the right cerebellum and the cerebellar midline also were active across task. These data are presented in Figure 5.

\section{Analysis of the Temporal Areas}

Many lesion-behavior studies and a number of imaging studies have attributed the activation in the superior temporal lobe to semantic processing (Price et al., 1997; Vandenberghe et al., 1996; Demonet et al., 1992; Wise et al., 1991). In the analysis described above, no regions in the temporal cortex displayed the pattern of activation expected for a region specifically involved in the analysis of meaning. To investigate more directly the role of the temporal regions in semantic processing, we took two different approaches. First, peak activations in the temporal lobes were identified with a visual analysis of the mean difference image for each condition, and the coordinates for those activations were determined. Mean activation and reliability of activation for each of these regions was then computed across the individual difference images in each condition. Only one region from the synonym-rhyme image $(-53,-47$, 
Table 4. Regions Active in All Four Conditions

\begin{tabular}{|c|c|c|c|c|c|c|c|}
\hline \multirow[b]{2}{*}{ Coordinates } & \multirow[b]{2}{*}{ Region } & \multicolumn{3}{|c|}{ Easy Categorization } & \multicolumn{3}{|c|}{ Hard Categorization } \\
\hline & & Mean & $S E$ & $p$ & Mean & $S E$ & $p$ \\
\hline$-29,19,-2$ & left frontal operculum & 38 & 14 & .007 & 67 & 12 & $<.0001$ \\
\hline$-37,-61,-12$ & left fusiform BA 37 & 70 & 14 & $<.0001$ & 60 & 18 & .0016 \\
\hline$-39,3,26$ & left precentral BA 6/44 & 76 & 11 & $<.0001$ & 79 & 14 & $<.0001$ \\
\hline$-49,13,20$ & left inferior frontal BA $44 / 45$ & 50 & 14 & .0014 & 71 & 13 & $<.0001$ \\
\hline$-5,-77,-20$ & medial cerebellum & 67 & 16 & .0002 & 84 & 15 & $<.0001$ \\
\hline$-53,-51,-16$ & left fusiform BA 37 & 47 & 14 & .0017 & 88 & 15 & $<.0001$ \\
\hline$-59,-35,-4$ & left middle temporal BA 21 & 46 & 12 & .0005 & 43 & 15 & .0055 \\
\hline$-7,-93,-6$ & left lingual BA 17 & 46 & 10 & .0001 & 59 & 12 & $<.0001$ \\
\hline $13,-83,-20$ & right posterior cerebellum & 44 & 16 & .0074 & 94 & 14 & $<.0001$ \\
\hline $15,-55,-18$ & right anterior cerebellum & 64 & 14 & .0001 & 89 & 20 & .0001 \\
\hline $17,-85,-10$ & left lingual BA 18 & 76 & 17 & .0002 & 72 & 16 & .0001 \\
\hline $3,31,28$ & anterior cingulate BA 32 & 48 & 14 & .0014 & 38 & 9 & .0004 \\
\hline \multirow{2}{*}{$7,-69,-18$} & right middle cerebellum & 63 & 15 & .0003 & 71 & 16 & .0001 \\
\hline & & \multicolumn{3}{|c|}{ Synonym } & \multicolumn{3}{|c|}{ Rbyme } \\
\hline Coordinates & Region & Mean & $S E$ & $p$ & Mean & $S E$ & $p$ \\
\hline$-29,19,-2$ & left frontal operculum & 73 & 17 & .0002 & 62 & 11 & $<.0001$ \\
\hline$-37,-61,-12$ & left fusiform BA 37 & 82 & 14 & $<.0001$ & 86 & 15 & $<.0001$ \\
\hline$-39,3,26$ & left precentral BA $6 / 44$ & 87 & 13 & $<.0001$ & 99 & 11 & $<.0001$ \\
\hline$-49,13,20$ & left inferior frontal BA $44 / 45$ & 55 & 22 & .0095 & 54 & 18 & .0035 \\
\hline$-5,-77,-20$ & medial cerebellum & 70 & 16 & .0002 & 72 & 19 & .0005 \\
\hline$-53,-51,-16$ & left fusiform BA 37 & 68 & 20 & .0016 & 56 & 13 & .0002 \\
\hline$-59,-35,-4$ & left middle temporal BA 21 & 55 & 16 & .0017 & 33 & 11 & .004 \\
\hline$-7,-93,-6$ & left lingual BA 17 & 34 & 11 & .0032 & 44 & 14 & .0023 \\
\hline $13,-83,-20$ & right posterior cerebellum & 71 & 18 & .0006 & 51 & 18 & .0061 \\
\hline $15,-55,-18$ & right anterior cerebellum & 71 & 17 & .0004 & 77 & 18 & .0002 \\
\hline $17,-85,-10$ & left lingual BA 18 & 66 & 12 & $<.0001$ & 52 & 17 & .0031 \\
\hline $3,31,28$ & anterior cingulate BA 32 & 70 & 17 & .0003 & 48 & 11 & .0002 \\
\hline $7,-69,-18$ & right middle cerebellum & 78 & 20 & .0005 & 59 & 14 & .0004 \\
\hline
\end{tabular}

-6), at or near BA 21 in the middle temporal gyrus, showed an activation pattern consistent with a role in semantic processing. The magnitude of this point did not exceed the threshold set during our initial screening, however, and analysis of the closest peak of activation in each of the four conditions revealed that this region did not correspond to a single peak activation common to the semantic tasks, but was rather a result of proximity to several different regions that were activated in the different tasks. Thus, no areas in the superior temporal cortex were found that are common to the semantic tasks, or for that matter, to all the language tasks.

In a second approach aimed at finding temporal activations related to semantics, 5 regions in the temporal and inferior parietal areas were identified in which significant activation was found in more than 1 of 15 previously reported task conditions requiring semantic analysis. The task comparisons included verb generation $(n=6)$, other types of word generation $(n=5)$, and yes/no decisions in the semantic domain $(n=4)$. The behavior of each of these regions in our data set of 


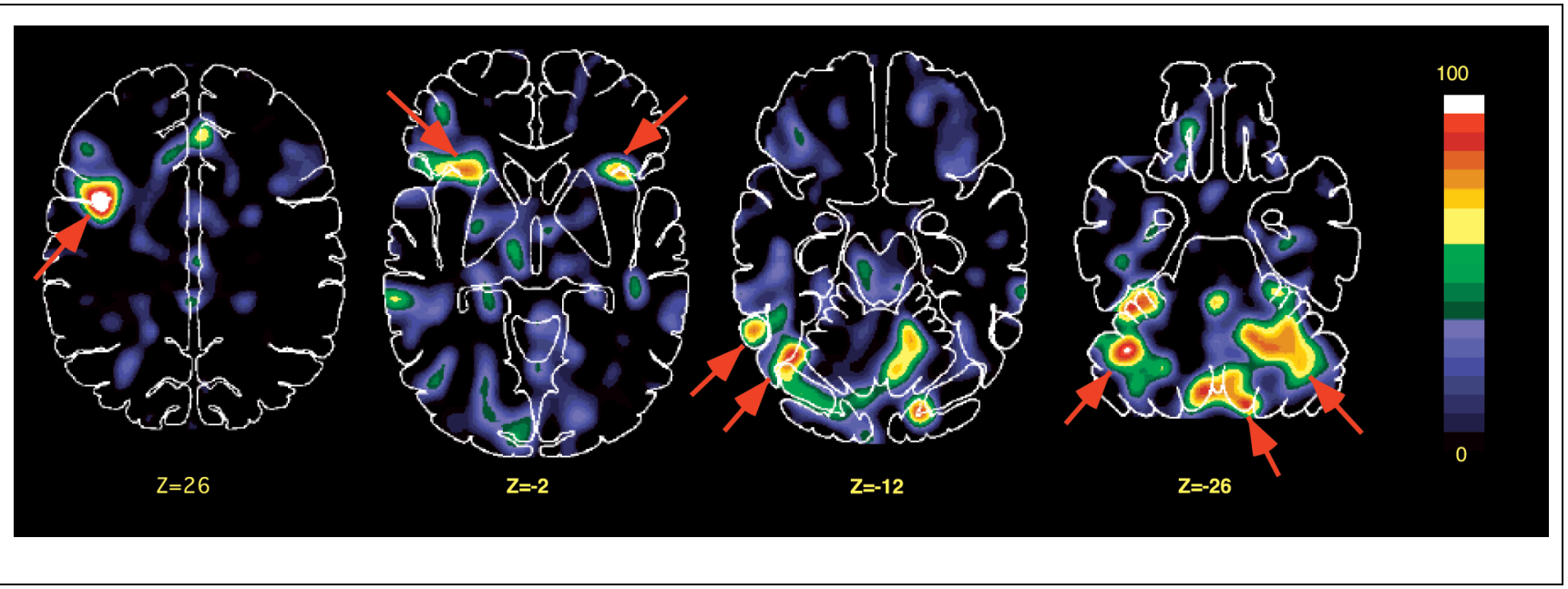

Figure 5. Regions active in all four conditions. Transverse slices showing regions of PET activation in a summed image across all 4 conditions with respect to fixation baseline. Arrows indicate significant activation at regions of particular interest.

semantic and nonsemantic conditions was computed. Although many of these regions were active in some of the tasks, none of those examined showed significant activation in the synonym and hard categorization, and not in rhyme, the pattern of activation one would expect of a region involved specifically in semantic analysis.

\section{Behavior of Identified Regions on Other Data Sets}

The 3 left inferior frontal and the right cerebellar regions identified as specifically associated with semantic processing were examined in other PET data sets acquired in this laboratory. None of the 4 areas identified was significantly active above baseline in either a picturenaming task, or in a task designed to explore the effects of word frequency and spelling-to-sound regularity in word reading, both tasks requiring minimal semantic analysis. In contrast, a one-sample $t$ test revealed that all 4 ROIs are significantly active above baseline in a data set acquired in which subjects had to generate a verb associated with a visually presented noun versus just reading the word. The medial opercular area was moderately active (average magnitude $=20, t(19)=1.92$, $p=.035$ ), while the lateral opercular region (average magnitude $=38, t(23)=5.24, p<.0001)$, the anterior region (average magnitude $=33, t(21)=3.65$, $p=.0008$ ), and the right cerebellar region (average magnitude $=50, t(13)=8.18, p<.0001$ ) were more strongly active.

\section{Examination of Sex Differences}

Our PET results on 10 men and 10 women provided an opportunity to explore whether significant differences in brain organization were evident between genders. Two-tailed paired $t$ tests on regional magnitudes in either of the categorization conditions for regions generated from the synonym-rhyme image revealed no sex differences. We also explored possible sex differences in all four language tasks for the temporal points gleaned from the literature, and again, found none. A region in the right frontal cortex has previously been reported to show a sex difference in a rhyming task (Shaywitz et al., 1995). In our data set, two regions of peak activation (17, 43, -14 and $15,41,-2)$ were found in the rhyme-fixation mean difference image, close to the right frontal region reported by Shaywitz et al. Contrary to expectations, a paired $t$ test revealed no difference between men and women in frontal areas in the rhyme task (for (17, $43,-14), t(15)=-1.47, p=.162$; for $(15,41,-2)$, $t(16)=-0.90, p=.929)$. The only observable sex differences appear to be slightly lower overall levels of regional activation, and somewhat more variability in activation patterns in women compared to men, in agreement with Buckner, Petersen, et al. (1995) and Buckner, Raichle, and Petersen (1995).

\section{DISCUSSION}

\section{Main Results of Current Study: Identification of Frontal Responses Specific to Semantic Tasks}

Using a converging operations approach, we have demonstrated activation in 3 left inferior frontal regions during 3 semantic tasks, but not in a comparison phonological task of similar difficulty. The specificity of their activation to semantic tasks strongly suggests that these areas subserve cognitive functions required during semantic processing specifically, rather than having a role in language processing more generally. Two of these left inferior frontal regions are modulated by a within-task manipulation of semantic demands, indicating that these closely apposed regions are functionally as well as spatially separable. In addition, the data 
suggest that rather than reflecting two different types of operations, the same frontal regions, and likely the same processes, subserve semantic processing regardless of whether the judgments required are highly associative or more evaluative and analytical.

Because the easy and hard categorization tasks employed exactly the same lexical items, task structure, and presentation parameters, it is difficult to attribute the results of the semantic manipulation to effects of specific lexical items or other surface features not central to the task; observed rCBF differences can most reasonably be attributed to the semantic analysis demands required to correctly perform the task. Two additional pieces of evidence argue against their being due to a generic measure of task difficulty. First, the synonym and rhyme tasks were of similar difficulty, but the left inferior frontal regions were only active in synonym, not rhyme. Second, on both RT and accuracy measures, rhyme was a more difficult task than easy categorization, yet the regions were more active in easy categorization than in rhyme.

\section{Identification of Frontal Responses in Phonological Task}

Regions in the left anterior and middle insula and left precentral gyrus at or near the Broca's area were preferentially active in the rhyme task. The left frontal opercular area, in general, has been associated with phonological processing (Fiez et al., 1995; Zatorre et al., 1992; for reviews, see Poldrack et al., 1999; Demonet, Fiez, Paulesu, Petersen, \& Zatorre, 1996; Zatorre, Meyer, Gjedde, \& Evans, 1996); the middle insula was also active in a silent counting task (Fiez et al., 1996) and during reading (Petersen et al., 1989). Regions in the left precentral gyrus have been postulated to be involved in "inner hearing" of phonological information (Paulesu et al., 1993; Zatorre et al., 1992) or in covert articulatory rehearsal (Fiez et al., 1995). Converging evidence thus points to an important role of the left opercular area in phonological processing (see Fiez, 1997).

\section{Regions Found in the Left Inferior Frontal Cortex are Functionally Dissociable}

This study demonstrates that the frontal cortex is composed of multiple regions that are functionally dissociable on the basis of their activation patterns across tasks, and are spatially distinct. This result illuminates much of the ongoing debate about the role of the frontal cortex, to which diverse functions have been attributed, ranging from phonological processing (Price et al., 1997; Paulesu et al., 1993, 1997; Zatorre et al., 1992), motor output (Wise et al., 1991; Geschwind, 1970), response selection (Thompson-Schill, D'Esposito, Aguirre, \& Farah, 1997; Thompson-Schill, D'Esposi- to, \& Kan, 1999), working memory (Goldman-Rakic, 1995; Petrides et al., 1993), memory retrieval (Wagner et al., 1997; Demb et al., 1995), and willed action (Frith, Friston, Liddle, \& Frackowiak, 1991). These conflicting claims may reflect a common conceptualization of the frontal cortex as a singular entity, or one divided into a handful of large functional subunits. Our results potentially lend functional significance to studies demonstrating differences in the anatomical connectivity of subregions of the frontal cortex (Brodmann; Carmichael \& Price, 1994; Petrides et al., 1993; GoldmanRakic, 1988). A fine-grained parsing of these areas is therefore functionally warranted and important for understanding the functional anatomy of complex processes such as language.

\section{Lack of Sex Differences in Regions of Semantic Task Specificity}

Contrary to other reports, paired comparisons between regions found to be specifically involved in the semantic or the rhyme tasks in women and men showed no significant differences in activation between sexes. An explicit comparison in our rhyme-fixation data set of the right frontal regions reported to differ between men and women in a rhyme judgment task (Shaywitz et al., 1995) revealed an essential uniformity in the activation of this region across genders.

\section{Temporal Regions Do Not Show Clear Specificity}

Lesion data and some neuroimaging results predict that the left superior temporal cortex would play a differential role in our semantic and nonsemantic tasks, but no evidence for this was found. However, the middle temporal gyrus (anterior and inferior to what is traditionally recognized as Wernicke's area) was active across all four tasks including the nonsemantic rhyme task, as was a region in the fusiform gyrus, which has been implicated in a variety of language tasks involving word reading (see Price et al., 1997; Petrides et al., 1993; Demonet et al., 1992; Wise et al., 1991; Petersen et al., 1988, 1989). The fusiform gyrus has been identified as a source of the N400 (McCarthy, Nobre, Bentin, \& Spencer, 1995), a signal associated with semantic processing. Our findings do not show clear specificity for this region for semantic processing. This may reflect a basal level of semantic processing that occurs in all lexical processing and is not subject to the task manipulations, or more general lexical processes. Other activations in the left temporal cortex differed across tasks (see also Thompson-Schill, et al., 1999; Chee, O'Craven, Bergida, Rosen, \& Savoy, 1999; Binder et al., 1997; Price et al., 1997) and thus were not identified in our analysis. Variation in the location of active foci in the superior temporal cortex among tasks suggests that the way these regions contribute to 
language processing may not map to simple conceptualizations of language localization. Thus, the left posterior temporal regions classically associated with semantic processing may play semantic roles other than the analysis of meaning required across our semantic tasks, for example in syntactic processing, or higher level integration of meaning across multiple words within and across sentences.

\section{The "Localization" of Semantics}

Our results are not easily reconcilable with the canonical view that semantic processing is subserved by the temporal lobe structures, raising the possibility that our data, or the lesion data supporting the involvement of the temporal areas in semantics, could be wrong.

Both of these possibilities seem highly unlikely. Abundant corroborating evidence from other imaging studies of semantically demanding tasks, including verb generation (Petersen et al., 1988, 1989; McCarthy et al., 1993), semantic encoding (Ricci et al., 1999; Wagner et al., 1997; Gabrieli et al., 1996; Demb et al., 1995), category judgments (Binder et al., 1997; Kapur et al., 1994), and language translation (Klein et al., 1995), all report activity in the left inferior frontal cortex during these tasks. In addition, semantic involvement of these regions is consistent with post hoc analysis of data from other neuroimaging experiments of language. The regions we identified were all significantly active in a semantically demanding verb generate task, but not in an orthographic/phonological word reading or a picture-naming task, both of which place less explicit demands on a semantic system. The disparity between our results and those reported by Price et al. (1997) may be explained by the differences between the respective tasks used: The semantic demands of our categorization and synonym tasks are greater than the demands of a living/nonliving decision.

Although lesion data show some semantic effects of frontal damage, the preponderance of evidence from lesion studies supports a role of the temporal cortex in semantic tasks. The challenge then, is to conceive accounts of semantic processing that are consistent with all the data. Following, we suggest and evaluate some frameworks for thinking about the role of frontal and temporal cortical areas in semantic processing.

\section{Is Semantic Processing Automatic?}

One potential explanation for the lack of differential activation in the temporal regions during semantic tasks is that the activity observed in the inferior and middle temporal regions across our semantic and nonsemantic tasks reflects obligatory or automatic semantic processing upon word presentation (Price, Wise, \& Frackowiak, 1996). Another explanation postulates that the semantic system, confined to the temporal lobe, is so widely distributed that the diffuse activity remains below thresholds set by our study and other neuroimaging studies. While both explanations cannot be dismissed, they must be incomplete, for they fail to explain the differential activation of left inferior frontal regions in semantic tasks, and in semantic difficulty manipulations: These regions still appear more explicitly tied to semantic demands. Thus, even if semantic processing is either automatic or widely distributed in the temporal lobe, it nonetheless appears localized and task-driven in frontal regions.

\section{Are Lexical and Sentential Semantics Dissociable?}

On the basis of ERP and PET data, Posner et al. suggest a model of semantic processing in which the frontal areas involved with processing individual word meaning are activated with short latency, and the temporo-parietal regions, which become active considerably later, are involved in integrating individual word meaning into the more complex, contextually sensitive, semantics of phrases and sentences (Posner, Abdullaev, McCandliss, \& Sereno, 1999; Abdullaev \& Posner, 1998; Snyder, Abdullaev, Posner, \& Raichle, 1995). This model is consistent with data presented here, with imaging studies of sentence processing that find considerable activation in the temporal lobe (Just, Carpenter, Keller, Eddy, \& Thulborn, 1996; Stromswold, Caplan, Alpert, \& Rauch, 1996), and it may be reconcilable with data from other lesion studies, in which lexical and sentential semantics are not always clearly delineated (for example, Mohr et al., 1978). However, there is some evidence for pure lexical semantic defects with temporal lobe damage (Hart \& Gordon, 1990), and this theory would imply that lexical semantics would be spared by temporal lobe lesions.

\section{Frontal Regions as Modality-Specific Control Areas}

An alternative type of explanation is that the frontal regions identified in this study are involved in control processes that interact with other brain regions, possibly those in the left temporal cortex, to access, select, gate, or retrieve semantic information from semantic stores (see also Wagner et al., 1997). Semantic processing may access information from multiple, widely distributed brain areas, possibly stored in cortical regions corresponding to the sensory modality characteristic of the type of information represented (Damasio, Grabowski, Tranel, Hichwa, \& Damasio, 1996; Vandenberghe et al., 1996; Martin, Haxby, Lalonde, Wiggs, \& Ungerleider, 1995; Damasio \& Tranel, 1993). This model is also consistent with data regarding relative timing of the frontal and temporo-parietal regions, and potentially with results of priming studies of lesion patients.

Frontal regions may subserve end-stage decision procedures on semantic information, such as determining 
whether some criterion has been met. These regions would then be working harder or longer in cases in which the semantic relationship between the stimuli is ambiguous or harder to determine, and would thus be more active in the difficult semantic conditions. Alternatively, these regions may be involved in reactivating semantic representations, perhaps by interacting with areas in the posterior temporal cortex. One may speculate that frontal regions interact directly with semantic stores, reactivating semantic information pertinent to the task. The potential diffuseness of the activity in this case may explain why no temporal regions were consistently activated across tasks. Frontal areas may instead interact with a posterior region that itself reconstitutes semantic content by activating the semantic stores, very similar to Damasio's idea of "convergence zones." This view could also account for the importance of a region in the temporal cortex for semantic processing, in general, though it does not explain the absence of consistent activation of such a locus in our data.

Recently, it has been proposed that the activity in the left inferior frontal cortex in semantic tasks is due to response selection or selection of information (Thompson-Schill et al., 1997, 1999). It is difficult to judge whether the results obtained in this study are consistent with a notion of selection among competing information. For example, one could argue that stimuli used in both the hard and easy conditions are associated with the same degree of competing information in both conditions, since both conditions use the same stimuli, yet we see differential activation in the tasks. One could also plausibly argue, however, that the degree to which various aspects of a semantic concept must be analyzed in the two conditions differs, with harder judgments requiring activation or selection of more attributes, and thus one might predict the pattern of activation seen here. Our results therefore are consistent with a conception of "selection among competing information" that involves domain specificity of the frontal regions. However, if Thompson-Schill intends such domain specificity, "selection of information" becomes virtually indistinguishable from semantic analysis more generally, and we are back to viewing the left inferior frontal region as a control region for semantic processing.

The view that the frontal areas act as control centers for language processing involves an important twist on an old idea. Frontal regions have been hypothesized previously to be involved, in general, in control processes (Duncan, Emslie, \& Williams, 1996; GoldmanRakic, 1995). Our data suggest an unanticipated specificity in the control processes: Different but closely apposed frontal regions may contribute differently to similar tasks with slightly different demands. The hypothesis of domain-specific control processes is one that prompts an extension of ideas about the nature of the frontal cortex and its role in cognitive processes.

\section{Conclusion}

Three regions in the left inferior frontal cortex and one in the right cerebellum are associated with semantic processing. These closely apposed regions in the frontal cortex are functionally distinct and distinguishable, and may be associated with very different tasks or be differentially modulated by changes in task demands. This suggests that in future efforts to functionally map the brain, the frontal cortex should be viewed as comprised of multiple, functionally distinct areas. In addition, these data call into question canonical views of semantic processing, suggesting instead that alternative models in which the frontal regions play a central role in the control or execution of semantic analysis may more accurately reflect the way the brain is organized to process language.

\section{METHODS}

\section{Subjects}

Data were analyzed from 20 healthy normal subjects (10 men, 10 women) aged 18-36 (mean age $=25 \pm 4$ ), recruited from the local community, and paid for their participation in the study. All were native English speakers with normal uncorrected vision, and strongly righthanded as determined by the Edinburgh Handedness Inventory (Raczkowski, Kalat, \& Nebes, 1974). All subjects gave informed consent in accordance with guidelines set by the Human Studies and the Radioactive Drug Research Committees of Washington University.

\section{Apparatus and Data Acquisition}

PET

The Siemens 961 scanner was used in 3-D mode to acquire 47 parallel slices simultaneously with a center-tocenter distance of $3.125 \mathrm{~mm}$. For each scan, water labeled with the positron-emitting oxygen isotope ${ }^{15} \mathrm{O}$ was used as a blood flow tracer. $\mathrm{H}_{2}{ }^{15} \mathrm{O}$ was incorporated into a sterile saline solution and administered as an intravenous bolus containing $12-16 \mathrm{mCi}$. Data were acquired over a 40-sec interval and reconstructed using filtered back projection with an in-plane resolution of 4 $\mathrm{mm}$. A linear relationship between blood flow and tissue radioactivity (Fox \& Mintun, 1989; Herscovitch, Markham, \& Raichle, 1983) allowed blood flow to be inferred from images of tracer distribution, eliminating the need for arterial catheterization. Intervals of 10-12 min between scans allowed radioactivity levels to return to baseline levels.

\section{Anatomical MR}

High resolution anatomical images of each subject's brain were acquired on a Siemens 1.5-T Magnetom MR scanner and headcoil. A TurboFlash pulse sequence with a flip angle of $8^{\circ}, \mathrm{TE}=4.0 \mathrm{msec}$, and $\mathrm{TR}=9.7 \mathrm{msec}$ was 
used to acquire a T1-weighted image with a voxel size of $1 \times 1 \times 1.25 \mathrm{~mm}$. MR scans were placed in Talairach space (Talairach \& Tournoux, 1988) with an image analysis package (Analyze, Rochester, MN) on the basis of the anterior and posterior commissure landmarks and brain dimensions.

\section{General PET Data Analysis Techniques}

Raw PET images were smoothed with a Butterworth filter (FWHM $=10.5 \mathrm{~mm}$ ). To control for the effects of variations in the amount of isotope injected and individual variation in blood flow, smoothed images were normalized to 1000 counts (Fox, Miezin, Allman, van Essen, \& Raichle, 1987). In addition, due to sampling characteristics of the PET scanner, the uppermost and lowermost slices were much noisier than those in the center. Consequently, the top 7 and bottom 7 slices were excluded from further analysis.

Each subject's PET scans were averaged together to produce an average within-subject blood flow image, and a rotation matrix was calculated that aligned the subject's averaged PET image with his or her anatomical MR scan in Talairach coordinates using the 6-parameter Automated Image Registration algorithm (Woods, Mazziotta, \& Cherry, 1993).

For each subject, movement between scan pairs was determined by a visually based rating system (Fox et al., 1987) and a mathematical algorithm. Individual scan pairs were excluded from further analysis on the basis of movement artifact; all results reported are computed only for scan pairs meeting the movement criteria.

Analysis was performed on difference images computed for pairs of scans, formed by subtracting, on a pixel-by-pixel basis, the filtered and registered image of one scan from another within each subject. Two types of analysis were performed: active condition versus baseline and active condition $\mathrm{A}$ versus active condition $\mathrm{B}$. Across-subject difference images of active conditions with respect to baseline were formed by computing an average of the scan pairs corresponding to a specific active condition minus each fixation, with each subject's data weighted equally. Weighted direct comparisons between two different active conditions were obtained by computing within-subject difference images for two different scan conditions, and weighting them so that each subject contributed equally to the resulting image (see Shulman, 1997, for description of weighting procedures).

\section{Identification and Analysis of Peak Activations}

Foci of change in difference images were determined using an automated peak detection algorithm (Mintun et al., 1989). For each peak, magnitude and location were computed. Each focus was used to define a spherical ROI with radius of $5 \mathrm{~mm}$, a sphere diameter commensurate with the resolution of the filtered images.

Spherical ROIs were then applied to individual difference images in various task conditions. Individual regional magnitude values were computed by calculating the average magnitude of all pixels falling within the spherical ROI in an individual difference image. Regional magnitude was calculated for each ROI in each individual difference image; values for each active scan versus each fixation image were averaged within a subject, and results from the two like active conditions were averaged to yield a mean regional activation for each of the 20 subjects. Due to variations in brain size and individual placement within the scanner, not all regions were fully sampled in all subjects. Individual regional data were included in further analysis for regions that were at least 90\% sampled; regions that were undersampled in $>75 \%$ of subjects were excluded from further analysis.

\section{Stimulus Presentation}

Word pairs were presented with a Macintosh computer (Macintosh 7100) on a monitor placed approximately 20 in. from the subjects in the PET scanner. Words appeared in 14-point bold capital letters above and below a centrally presented fixation cross. The top word appeared first; the bottom word appeared after a 250-msec delay. Both words disappeared $500 \mathrm{msec}$ later. A new pair was presented every 3 sec.

\section{Stimuli}

Stimuli for each pair of tasks were matched on a number of characteristics and parameters, so that differences in activation evident upon direct comparisons between the tasks would reflect task-related differences in processing, rather than incidental differences in surface features. All stimulus words were nouns, matched for word frequency (Francis \& Kucera, 1982) and word length across lists. Word lists were identical for the easy and hard categorization conditions (frequency of pairs = $64 \pm 76 S D$; average length of pairs $=12.3 \pm 3.0 S D)$. The stimuli for the synonym (frequency of pairs [incidence per million words] $=71 \pm 94 S D$; average length of pairs [in letters] $=10.4 \pm 2.0 S D$ ) and rhyme (frequency of pairs $=67 \pm 59 S D$; average length of pairs $=10.3 \pm 2.5 S D$ ) were matched as closely as possible with the stimuli for the categorization tasks. Differences in word frequency between any of these tasks were not significant.

\section{Scan Order}

Before scanning, a block of lexical decision trials was given to each subject to acquaint them with the timing of stimulus presentation and the keys on the response 
keypad. In addition, each scan block was preceded by a practice block of 10-12 trials similar to the upcoming block to ensure that subjects understood the task and performed accurately. Erroneous responses during practice blocks elicited an auditory feedback beep. Feedback was not given during scan blocks. No items used in practice blocks were used in scan blocks.

Each subject performed each task (synonym, rhyme, hard categorization, easy categorization) twice, and performed a fixation task (baseline control condition) three times, for a total of 11 scans. Task pairs were alternated in blocks, for an ABABCDCD design, and both pair order and block order were counterbalanced across subjects. Each subject saw all items in the synonym and rhyme corpus, all category names once, and half the category items. Every two subjects saw all category items, and every four subjects saw all category/item pairings. No word was presented more than once to a subject.

\section{Acknowledgments}

This work was supported by NIH grants NS06833 and NS32979 and the Charles A. Dana Foundation.

Reprint request should be sent to Steven E. Petersen, Department of Neurology and Neurosurgery and Department of Radiology, Washington University School of Medicine, $660 \mathrm{~S}$. Euclid, St. Louis, MO 63110, USA, or via e-mail: sep@petcn. wustl.edu.

\section{REFERENCES}

Abdullaev, Y., \& Posner, M. I. (1998). Event-related brain potential imaging of semantic encoding during processing of single words. Neuroimage, 7, 1-13.

Binder, J. R., Frost, J. A., Hammeke, T. A., Cox, R. W., Rao, S. M., \& Prieto, T. (1997). Human brain language areas identified by functional magnetic resonance imaging. Journal of Neuroscience, 17, 353-362.

Buckner, R. L., Petersen, S. E., Ojemann, J. E., Miezin, F. M., Squire, L. R., \& Raichle, M. E. (1995). Functional anatomical studies of explicit and implicit memory retrieval tasks. Journal of Neuroscience, 15, 12-29.

Buckner, R. L., Raichle, M. E., \& Petersen, S. E. (1995). Dissociation of human prefrontal cortical areas across different speech production tasks and gender groups. Journal of Neurophysiology, 74, 2163-2173.

Carmichael, S. T., \& Price, J. L. (1994). Architectonic subdivision of the orbital and medial prefrontal cortex in the macaque monkey. Journal of Comparative Neurology, 346, 366-402.

Chee, M. W., O'Craven, K. M., Bergida, R., Rosen, B. R., \& Savoy, R. L. (1999). Auditory and visual word processing studied with fMRI. Human Brain Mapping, 7, 15-28.

Damasio, A. R., \& Tranel, D. (1993). Nouns and verbs are retrieved with differently distributed neural systems. Proceedings of the National Academy of Sciences, U.S.A., 90, 4957-4960.

Damasio, H., Grabowski, T. J., Tranel, D., Hichwa, R. D., \& Damasio, A. R. (1996). A neural basis for lexical retrieval. Nature, 380, 499-505.

Demb, J. B., Desmond, J. E., Wagner, A. D., Vaidya, C. J., Glover, G. H., \& Gabrieli, J. D. E. (1995). Semantic encoding and retrieval in the left inferior prefrontal cortex: A functional
MRI study of task difficulty and process specificity. Journal of Neuroscience, 15, 5870-5878.

Demonet, J. F., Chollet, F., Ramsay, S., Cardebat, D, Nespoulous, J. L. Wise, R., Rascol, \& A, Frackowiak R. (1992). The anatomy of phonological and semantic processing in normal subjects. Brain, 115, 1753-1768.

Demonet, J. F., Fiez, J. A., Paulesu, E., Petersen, S. E., \& Zatorre, R. J. (1996). PET studies of phonological processing: A critical reply to Poeppel. Brain and Language, 55, 352-279.

Duncan, J., Emslie, H., \& Williams, P. (1996). Intelligence and the frontal lobe: The organization of goal-directed behavior. Cognitive Psychology, 30, 257-303.

Fiez, J. A. (1996). Cerebellar contributions to cognition. Neuron, 16, 13-15.

Fiez, J. A. (1997). Phonology, semantics, and the role of the left inferior prefrontal cortex. Human Brain Mapping, 5, 79-83.

Fiez, J. A., Raichle, M. E., Miezin, F. M., Petersen, S. E., Tallal, P., \& Katz, W. F. (1995). PET studies of auditory and phonological processing: Effects of stimulus characteristics and task demands. Journal of Cognitive Neuroscience, 7 , 357-375.

Fiez, J. A., Raife, E. A., Balota, D. A., Schwartz, J. P., Raichle, M. E., \& Petersen, S. E. (1996). A positron emission tomography study of the short-term maintenance of verbal information. Journal of Neuroscience, 16, 808-822.

Fox, P. T., Miezin, F. M., Allman, J. M., van Essen, D. C., \& Raichle, M. E. (1987). Retinotopic organization of human visual cortex mapped with positron emission tomography. Journal of Neuroscience, 7, 913-922.

Fox, P. T., \& Mintun M. A. (1989). Noninvasive functional brain mapping by change distribution analysis of averaged PET images of $\mathrm{H}_{2}{ }^{15} \mathrm{O}$ tissue activity. Journal of Nuclear Medicine, 30, 141-149.

Francis, W. N., \& Kucera, H. (1982). Frequency analysis of English usage. Boston: Houghton Mifflin.

Frith, C. D., Friston, K., Liddle, P. F., \& Frackowiak, R. S. J., (1991). Willed action and the prefrontal cortex in man: A study with PET. Proceedings of the Royal Society of London, Series B: Biological Sciences, 244, 241-246.

Gabrieli, J. D. E., Desmond, J. E., Demb, J. B., Wagner, A. D., Stone, M. V., Vaidya, C. J., \& Glover, G. H. (1996). Functional magnetic resonance imaging of semantic memory processes in the frontal lobes. Psychological Science, 7, 278-283.

Geschwind, N. (1970). The organization of language and the brain. Science, 170, 940-944.

Goldman-Rakic, P. (1988). Topography of cognition: Parallel distributed networks in primate association cortex. Annual Review of Neuroscience, 11, 137-156.

Goldman-Rakic, P. (1995). Cellular basis of working memory. Neuron, 14, 477-485.

Hart, J., \& Gordon, B. (1990). Delineation of single-word semantic comprehension deficits in aphasia, with anatomical correlation. Annals of Neurology, 27, 226-231.

Herscovitch, P, Markham, J., \& Raichle, M. E. (1983). Brain blood flow measured with intravenous $\mathrm{H}_{2}^{15} \mathrm{O}$ : I. Theory and error analysis. Journal of Nuclear Medicine, 24, 782-789.

Just, M. A., Carpenter, P. A., Keller, T. A., Eddy, W. F., \& Thulborn, K. R. (1996). Brain activation modulated by sentence comprehension. Science, 274, 114-116.

Kapur, S., Rose, R., Liddle, P. F., Zipursky, R. B., Brown, G. M., Stuss, D., Houle, S., \& Tulving, E. (1994). The role of the left prefrontal cortex in verbal processing: Semantic processing or willed action? NeuroReport, 5, 2193-2196.

Klein, D., Milner, B., Zatorre, R. J., Meyer, E., \& Evans, A. C. (1995). The neural substrates underlying word generation: A bilingual functional-imaging study. Proceedings of the $\mathrm{Na}$ tional Academy of Sciences, U.S.A., 92, 2899-2903.

Martin, A., Haxby, J. V., Lalonde, F. M., Wiggs, C. L., \& Unger- 
leider, L. G. (1995). Discrete cortical regions associated with knowledge of color and knowledge of action. Science, 270, 102-105.

McCarthy, G., Blamire, A. M., Rothman, D. L., Gruetter, R., \& Shulman, R. G. (1993). Echo-planar magnetic resonance imaging studies of frontal cortex activation during word generation in humans. Proceedings of the National Academy of Sciences, U.S.A., 90, 4952-4956.

McCarthy, G., Nobre, A. C., Bentin, S., \& Spencer, D. D. (1995). Language-related field potentials in the anterior-medial temporal lobe: I. Intracranial distribution and neural generators. Journal of Neuroscience, 15, 1080-1089.

Mintun, M. A., Fox, P. T., \& Raichle, M. E. (1989). A highly accurate method of localizing regions of neuronal activation in the human brain with positron emission tomography. Journal of Cerebral Blood Flow and Metabolism, 9, 96-103.

Mohr, J. P., Pessin, M. S., Finkelstein, S., Funkenstien, H. H., Duncan, G. W., \& Davis, K. R. (1978). Broca aphasia: Pathologic and clinical. Neurology, 28, 311-324.

Paulesu, E., Frith, C. D., \& Frackowiak, R. S. (1993). The neural correlates of the verbal component of working memory. Nature, 362, 342-345.

Paulesu, E., Goldacre, B., Seifo, P., Cappa, S. F., Gilardi, M. C., Castiglioni, I., Perani, D., \& Fazio, F. (1997). Functional heterogeneity of left inferior frontal cortex as revealed by fMRI. NeuroReport, 8, 2011-2017.

Petersen, S. E., Fox, P. T., Posner, M. I., Mintun, M., \& Raichle, M. E. (1988). Positron emission tomographic studies of the cortical anatomy of single word processing. Nature, 331, 585-589.

Petersen, S. E., Fox, P. T., Posner, M. I., Mintun, M., \& Raichle, M. E. (1989). Positron emission tomographic studies of the processing of single words. Journal of Cognitive Neuroscience, 1, 153-170.

Petersen, S. E., Fox, P. T., Snyder, A. Z., \& Raichle, M. E. (1990). Activation of extrastriate and frontal cortical areas by visual words and word-like stimuli. Science, 249, 1037-1041.

Petrides, M., Alivasatos, B., Meyer, E., \& Evans, A. C. (1993). Functional activation of the human frontal cortex during the performance of verbal working memory tasks. Proceedings of the National Academy of Sciences, U.S.A., 90, 878-882.

Poldrack, RA, Wagner A. Z., Prull, M. W., Desmond, J. E., Glover, G. H., \& Gabrieli, J. D. E. (1999). Functional specialization for semantic and phonological processing in the left inferior prefrontal cortex. Neuroimage, 1-22.

Posner, M. I., Abdullaev, Y. G., McCandliss, B. D., \& Sereno, S. C. (1999). Anatomy, circuitry and plasticity of word reading. In J. Everatt (Ed.) Reading and dyslexia: Visual and attentional processes. London: Routledge.

Price, C. J., Moore, C. J., Humphreys, G. W., \& Wise, R. J. S. (1997). Segregating semantic from phonological processes during reading. Journal of Cognitive Neuroscience, 9, $727-733$.
Price, C. J., Wise, R. J., \& Frackowiak, R. S. (1996). Demonstrating the implicit processing of visually presented words and pseudowords. Cerebral Cortex, 6, 62-70.

Raczkowski, D., Kalat, J. W., \& Nebes, R. (1974). Reliability and validity of some handedness questionnaire items. Neuropsychologia, 12, 43-47.

Ricci, P. T., Zelkowicz, B. J., Nebes, R. D., Meltzer, C. C., Mintun, M. A., \& Becker, J. T. (1999). Functional neuroanatomy of semantic memory: Recognition of semantic associations. Neuroimage, 9, 88-96.

Shaywitz, B. A., Shaywitz, S. E., Pugh, K. R., Constable, R. T., Skudlarski, P., Fulbright, R. K., Bronen, R. A., Fletcher, J. M., Shankweller, D. P., Katz, L., \& Gore, J. C. (1995). Sex differences in the functional organization of the brain for language. Nature, 373, 607-609.

Shulman, G. (1997). Top-down modulation of early sensory cortex. Cerebral Cortex, 7, 193-206.

Snyder, A. Z., Abdullaev, Y., Posner, M. I., \& Raichle, M. E. (1995). Scalp electrical potentials reflect regional cerebral blood flow responses during processing of written words. Proceedings of the National Academy of Sciences, U.S.A., 92, 1689-1693.

Stromswold, K., Caplan, D., Alpert, N., \& Rauch, S. (1996). Localization of syntactic comprehension by positron emission tomography. Brain and Language, 52, 452-473.

Talairach, J., \& Tournoux, P. (1988). Co-planar stereotactic atlas of the human brain. New York: Thieme.

Thompson-Schill, S. L., D'Esposito, M., Aguirre, G. K., \& Farah, M. J. (1997). Role of left inferior prefrontal cortex in retrieval of semantic knowledge: A re-evaluation. Proceedings of the National Academy of Sciences, U.S.A., 94, 14792-14797.

Thompson-Schill, S. L., D'Esposito, M., \& Kan, I. P. (1999). Effects of repetition and competition on activity in left prefrontal cortex during word generation. Neuron, 23, 513-22.

Vandenberghe, R., Price, C., Wise, R., Josephs, O., \& Frackowiak, R. S. J. (1996). Functional anatomy of a common semantic system for words and pictures. Nature, 383, 254-256.

Wagner, A. D., Desmond, J. E., Demb, J. B., Glover, G. H., \& Gabrieli, J. D. E. (1997). Semantic repetition priming for verbal and pictorial knowledge: A functional MRI study of left inferior prefrontal cortex. Journal of Cognitive Neuroscience, 9, 714-726.

Wise, R., Chollet, F., Hadar, U., Friston, K., Hoffner, E., \& Frackowiak, R. (1991). Distribution of cortical neural networks involved in word comprehension and word retrieval. Brain, 114, 1803-1817.

Woods, R. P., Mazziotta, J. C., \& Cherry, S. R. (1993). MRI-PET registration with automated algorithm. Journal of Computer Assisted Tomography, 17, 536-546.

Zatorre, R. J., Evans, A. C., Meyer, E., \& Gjedde, A. (1992). Lateralization of phonetic and pitch discrimination in speech processing. Science, 256, 846-849.

Zatorre, R. J., Meyer, E., Gjedde, A., \& Evans, A. C. (1996). PET studies of phonetic processing of speech: Review, replication, and reanalysis. Cerebral Cortex, 6, 21-30. 